\title{
Artelogie
}

Recherche sur les arts, le patrimoine et la littérature de l'Amérique latine

2 | 2012

Mexique : espace urbain et résistances artistiques et littéraires face à la « ville générique »

\section{El DF en tono apocalíptico. La literatura mexicana de ciencia ficción y la Ciudad de México}

Itala Schmelz

\section{OpenEdition}

Journals

Edición electrónica

URL: https://journals.openedition.org/artelogie/7693

DOI: $10.4000 /$ artelogie.7693

ISSN: $2115-6395$

Editor

Association ESCAL

Referencia electrónica

Itala Schmelz, «El DF en tono apocalíptico. La literatura mexicana de ciencia ficción y la Ciudad de México», Artelogie [En línea], 2 | 2012, Publicado el 21 enero 2012, consultado el 07 enero 2022. URL: http://journals.openedition.org/artelogie/7693 ; DOl: https://doi.org/10.4000/artelogie.7693

Este documento fue generado automáticamente el 7 enero 2022.

Association ESCAL 


\title{
El DF en tono apocalíptico. La literatura mexicana de ciencia ficción y la Ciudad de México
}

\author{
Itala Schmelz
}

"La ciudad de México día a día se precipita a su final y, también a diario, se reconstituye con la energía de las multitudes convencidas de que no hay ningún lugar a dónde ir". Carlos Monsiváis, "Apocalipstik" (2009)

1 Las grandes ciudades expresan el poder y los alcances de una civilización, son hogar y escenario del drama y del quehacer de sus habitantes, en ellas se concentra la simbolización que nos arraiga en una identidad, en una época y una cultura específica. En la urbe se aglomeran, así mismo, un cúmulo inagotable de necesidades e intereses; el tráfico de personas, saberes y "valores, va generando enjambres y tejidos sociales sumamente complejos, la ciudad se vuelve laberinto. Es curioso que con tanto afán estas se construyan y que la pulsión por su destrucción sea tan fuerte. Un escenario recurrente de la ciencia ficción es la de la representación de la destrucción final de una ciudad, la suspensión de lo cotidiano por un estado de emergencia que pone en riesgo todo lo que conocemos como modo de vida.

2 Hay ciudades, como Nueva York, que han sido visualizadas paradigmáticamente para representar el fin del mundo, pero ¿Cómo se desarrolla el Apocalipsis en otras ciudades? Me propongo comentar ocho cuentos de ciencia ficción mexicana que especulan, de manera prospectiva, sobre el futuro de la Ciudad de México. En cada una de estas historias se representa una situación apocalíptica en el Distrito Federal (DF), metrópoli que, si bien no cuenta con la abundante producción literaria y cinematográfica que en este tema tiene la ciudad de Nueva York, tiene muchos 
elementos para calificar como una urbe al borde del caos, sin necesidad de fantasía o ficción.

3 La literatura mexicana de este género es más extensa y audaz de lo que en primera instancia se pudiera pensar, a pesar del lugar marginal que se le ha dado dentro de la historia de nuestras letras. Los concursos, las compilaciones, colaboraciones con revistas de ciencia y tesis sobre el tema, de los cuales apenas pude revisar someramente una parte, dan cuenta de esta vitalidad. ${ }^{1}$ Esta literatura no se caracteriza tanto por su interés en las innovaciones y los avances tecnológicos, como por su preocupación en torno a los aspectos políticos y sociales del devenir; y a diferencia de la anglosajona, que no puede evitar la tentación de involucrar a un héroe salvador y el consabido final feliz, la mexicana es una ciencia ficción extremadamente pesimista; sus autores, señala Gabriel Trujillo: "Nos ofrecen una visión descarnada, sin filtros de ninguna especie, de la vida mexicana en un futuro apocalíptico, donde la lucha por la sobrevivencia en la ciudad de México no da lugar para el amor y la esperanza." ${ }^{2}$

4 En alguna medida, cualquier ciencia ficción se queda corta ante la realidad contemporánea de esta hiper-ciudad. Quien quisiera racionalizarla, sin duda caería en la locura o el surrealismo. Si algunas de las ciudades primer mundistas son punta de lanza de lo promisorio, la ciudad de México en cambio, al tiempo que no ha cumplido sus promesas de modernidad, revela ya su condición posmoderna. Carlos Monsiváis, en su libro Apocalisptik, asegura que "Esta ciudad ya está viviendo en el presente de un mundo alternativo. La Ciudad de México es ya postradicional." ${ }^{3}$ Y preguntándose por la pertinencia de llamarla posmoderna, siendo que se suele definir que una ciudad tercermundista tiene por meta la modernidad, el analista argumenta: "se puede hablar de sociedad posmoderna porque las masas, aprovechándola o no, asimilándola o no, rebasan la modernidad disponible." ${ }^{4}$

5 Si las utopías del progreso toman como ciudad modelo a los países del norte, la ciudad de México sería su opuesto. Las historias que vamos a comentar, hablan del tipo de futuro que se desarrolla hacia las faldas de la modernidad, en su patio trasero. Tienen su propia expresión y es la expresión del caos y el descontento. El DF, como Sao Paulo, Buenos Aires o Caracas, se caracteriza por sus contrastes entre riqueza y pobreza, por el culto gubernamental a la modernidad y la proliferación de franquicias tipo McDonald's, el crecimiento de la economía informal, los "espectaculares" de publicidad como ventana impúdica de los bienes inalcanzables, etc.

6 “¿Cómo no admirar la coexistencia de millones de personas en medio de los desastres en el suministro de agua, en vivienda, en el transporte, en las opciones de trabajo, en la seguridad pública?"5 exclama Monsiváis, y Pepe Rojas acierta cuando dice que: "la ciencia ficción mexicana comenzó a madurar el día que se bajó de la nave espacial y se subió al metro"6. Este género ha surgido para reflexionar sobre el presente, para poner en juego los temores que genera la sociedad actual y, si bien sus autores han sido una "cofradía de fantasmas", en conjunto reúnen una sólida visión fatalista de la ciudad capital.

\section{2}

7 En estas historias, es poco común que la ciudad sea atacada por extraterrestres con la excepción del cuento de Héctor Chevarria, "De cómo el Roñas y su mamá salvaron al mundo"8, en el que los Linx llegan al DF con el propósito de conquistar el planeta y de 
utilizar a los humanos como abono. Dos tripulantes aterrizan en Tepito, barrio bravo de la ciudad, escondite de maleantes y cuna de prostitución, y se encuentran con el Roñas, un teporocho ${ }^{9}$ que ronda por las calles oscuras bien cruzado con mota, cemento y alcohol del 96, quien los toma por "gringos" y los invita a comer a casa de su mamá. La doña les recalienta uno antojitos mexicanos, mientras el hijo les da a probar un surtido de estupefacientes, que bastaron para eliminarlos mientras que su nave, estacionada en un terreno baldío, es deshuesada (desmantelada) y las partes vendidas en un tianguis. ¡Es así como sin saberlo, un pelado mexicano salvó al mundo!

8 En el cuento de Gonzalo Martré "Los antiguos mexicanos a través de sus ruinas y sus vestigios", se concluye que los mexicanos desaparecieron matándose los unos a los otros y descuidaron su país y su ecología. Es el año 2910, el país y la cultura mexicana han desaparecido y la Fundación Gandhi organiza una expedición de arqueólogos y especialistas, para buscar más información sobre dicha cultura, de la cual únicamente se conservan tres películas: "Vámonos con Pancho Villa" de Fernando de Fuentes, "Charros vs Gansters" de Juan Orol y "Las Ficheras" de Miguel M. Mercado, así como un tomo completo de la revista "Alarma", 52 números correspondientes al año 1993 en microfilm. A partir de los documentos conservados, los científicos de la expedición tienen varias tesis diferentes respecto a cómo desaparecieron los mexicanos: Según Marija Lourencac, socióloga rubia de dos metros de altura, "Los mexicanos se habían extinguido asesinándose entre sí por causas baladíes", mientras que el sexólogo húngaro, Jano Nagy "fundaba en la lujuria la desaparición de los mexicanos: ¡Los antiguos mexicanos, como grandes fornicadores, sobrepoblaron el país a tal grado que murieron por falta del espacio vital !". Para el historiador Joseph Beac: "Los mexicanos se acabaron por su nulo sentido de visión histórica, vivían para el presente y el futuro los ahogó"10.

9 La expedición "quiso desenterrar los restos de las principales ciudades de México: DF, Guadalajara y Monterrey, pero 800 años de erosión fueron demasiados siglos y como los edificios se construyeron con especificaciones alteradas del cemento, varilla y viguetas, en los primeros 300 años de abandono quedaron reducidos a polvo impalpable" ${ }^{11} \mathrm{En}$ esta ficción se usa la proyección al futuro para hacer un retrato irónico del presente, específicamente de la corrupción y violencia que permean todos los aspectos de nuestra cotidianidad; este género de ciencia ficción cómica logra, a través de la risa, producir conciencia y reflexión.

Mientras que la historia de José Emilio Pacheco, "La catástrofe", es una especie de fábula moral o hasta moralizante. El autor señala, más que a la debilidad del ejército, a la desidia y el malinchismo de los mexicanos, como responsables de la invasión de una potencia extranjera. Pacheco escribe: "El centinela lleva al hombro una de aquellas armas ultrasónicas que desde lejos segaban regimientos enteros"12. Estas armas ultrasónicas son la única parafernalia que nos ayuda a suponer un futuro tecnologizado o la aparición de ejércitos, quizá no de otro país, sino intergalácticos. El caso es que: "Nos hundieron la misma somnolencia lúgubre, el tedio, la indecisión, la ausencia de energía, la indiferencia clínica, el relajamiento de la voluntad (...) Nadie pensaba en resistir -el egoísmo se levantaba feroz-, el odio al enemigo no era por la pérdida de la patria, sino por los desastres particulares que traía consigo"13. Pacheco reformula lo que pudo haber sido cuando el ejército norteamericano entró hasta home run en 1847, y concluye su historia: "Diariamente llevo a mis hijos a la ventana y les enseño el 
centinela del Castillo. Les cuento la trágica historia y les hago desear el día en el que vean de nuevo en Chapultepec un centinela mexicano." ${ }^{14}$

\section{3}

11 La reseña de la destrucción del espacio público y arquitectónico abunda en las fábulas futuristas, llenas de imágenes lúgubres y desoladoras, afincadas en lugares muy conocidos e icónicos de la Ciudad: Chapultepec, la avenida Reforma, el Zócalo y la Basílica, apuntalan la geografía específica donde acontece el porvenir. La fuente de destrucción puede ser la caída inminente de un meteorito. Argumento nodal de la ciencia ficción internacional para poner en escena una catástrofe llena de destrucción y muerte, como lo ha hecho Hollywood en la gran pantalla. Pero la versión mas reiterada en la ficción mexicana es la del movimiento telúrico. Si Nueva York cuenta con su destrucción terrorista de las torres gemalas del once de septiembre de 2001, el terremoto que sufrió nuestra ciudad el 19 de septiembre de 1985 quedó grabado en la historia nacional como el escenario de la catástrofe más doloroso y significativo.

En "El año de los gatos amurallados" Ignacio Padilla describe "La ciudad devastada primero por el terremoto y luego por sus habitantes." Una urbe abandonada por la razón y sumergida en la anarquía: "en la que poco a poco la autoridad se había desintegrado para dejar que los saqueadores erigiesen sus bastiones de poder en todas partes... Los antiguos palacios de gobierno se habían transformado en garitas del caos." ${ }^{15}$ En este cuento sin concesiones, la suspensión perversa de los límites que rigen la normalidad, arroja de nuevo a la humanidad hacia la barbarie y el canibalismo. Los sobrevivientes se esconden bajo tierra, en las estaciones del metro. ¿Quién llevaría unos muebles al subterráneo tratando de recrear ahí dentro una cotidianeidad perdida? Que bueno que estaban ahí, ya que sirvieron de barricada para defenderse efímeramente de las enormes bandas de gatos hambrientos, con sus feroces fauces tras la carne caliente de los pocos humanos que aún vivían: "Los animales eran lo otro, representaban lo desesperado de la situación, eran los dueños de esa parte de aquel mundo subterráneo y pronto lo serían también de la superficie."16

Bernardo Fernández (el Bef) recrea en "Las últimas horas de los últimos días", a dos personajes entrañables: Wok y Aída, quienes crecieron al filo del nuevo milenio en una sociedad regida por paradigmas muertos, sin un futuro que ofrecerles. Los jóvenes pasan juntos las pocas horas que quedan antes de que un meteorito caiga destruyendo la vida en el planeta. "El chingadazo ya viene", "ahora si ya valió madres, se acabó el mundo" el presente es pura adrenalina y hay que gastar las horas con intensidad. "Dejamos la moto a los pies del Caballito de Sebastián. Antes era una escultura amarillo brillante, ahora es una mole herrumbrosa que obstruye avenida Reforma, como casi todas las demás estatuas que habíamos estado jugando a esquivar desde que nos encontramos la moto." ${ }^{17}$

Los jóvenes recorren la urbe, experimentando la libertad y el deseo, en medio de los edificios, espacios públicos y centros comerciales abandonados, que se han quedado ahí, como un gran cuarto de juegos desordenado, permitiendo que los adolescentes exploren su amor a la vida a las postres del negro total. Duermen en un hotel vacío, donde las habitaciones de los pisos más altos estaban intactas pues no fueron saqueadas, y desde ahí contemplan la ciudad: "Todo estaba obscuro, ni siquiera se veían las fogatas que a veces brillan en los edificios. Nos sentimos muy solos." 18 
"Nos despertó el ruido de una procesión que marchaba hacia el norte por Reforma. Me imagino que irían hacia el Cerro del Tepeyac, desde que se supo lo del meteorito, la Villa se había convertido en el destino obligado de las miles de sectas surgidas ante la inminencia del final." ${ }^{19}$ Ellos, enamorados, pasean en patineta por el Bosque de Chapultepec, "Los troncos resecos que quedaban de él" ${ }^{20}$, suben al mirador y se ponen los lentes oscuros que ella tomó de algún almacén, para contemplar el gran espectáculo de las bolas de fuego impactando nuestra Tierra. Se besan justo en el momento del estruendo final.

\section{4}

En algunas de las historias leídas, aparecen trastocados signos de milenarismo o mesianismo new age, por ejemplo, la aparición del mito en torno a los volcanes que vigilan el valle y a través de los cuales atravesó Hernán Cortes contemplando por primera vez Tenochtitlan. La leyenda dice que el Popocatpetl y el Iztazihuatl, como bien representan los cromos de Jesús Helguera ${ }^{21}$, son una princesa y un guerrero aztecas dormidos. Su despertar dará comienzo al cataclismo que hundirá en lava y cenizas a la ciudad del pecado. A su vez, el lago ancestral en el que se fundara la ciudad, que quedó bajo la urbe. La capital del gran reino azteca, que fuera sometida y conquistada por los españoles, se sacudirá la imposición de occidente, superando la historia de dominio y postración. En un futuro emponzoñado por la modernidad que trajo occidente, renacerán los dioses de esta tierra y ahogarán a la capital en sus inmundicias. De esa catarsis resurge cual ave fénix el lago originario y la calma vuelve al valle, tal como el día en que sobre un nopal se posara un águila, devorando una serpiente.

El lago mítico de la fundación del imperio Azteca, resurge también en las premoniciones de una médium, ama de casa de un barrio marginado, Cristina Leguízamo, quien además de contactar con seres del Centurión de Orión, "en 1978 predijo que el valle de México viviría un terremoto devastador que abriría grietas de afluentes subterráneos conectados con el océano pacífico. En suma, sin especificar fecha, anticipó que el valle de México volverá a ser lago, así como lo fue antes de la conquista" ${ }^{22}$ De esta idea parte la novela "Tiempo lunar", de Mauricio Molina.

Andrés es un personaje detectivesco y alcohólico, que va en búsqueda de Ismael, su amigo desaparecido misteriosamente, quien dejó como pista una bitácora de lugares de la ciudad con el acceso restringido. "Desde hacía años, grandes regiones de la ciudad habían sido evacuadas por órdenes superiores, nadie sabía a ciencia cierta cuál era la causa real...Los policías y militares tomaron el mando de la ciudad. Lo que había sido el corazón del país se convirtió en un tumor del que nadie quería o podía hacerse responsable. A principios del siglo, la ciudad había llegado a tener 30 millones de habitantes. En menos de 20 años la mancha urbana había reducido su población a unos cuantos cientos de miles. Muy pocos decidieron quedarse a habitar un cadáver en ruinas." ${ }^{23}$

19 Siguiendo la bitácora de Ismael, Andrés se va topando con las zonas prohibidas de la ciudad, hasta que descubre que esta se está sumergiendo en un lago verde y ávido de vida pantanosa, con corrientes subterráneas que arrastran objetos y personas. El agua va ganando terreno a la urbe, calles y zonas enteras desaparecen de un día al otro: "El Zócalo era ya una enorme laguna", "era un lago inmenso y estancado que se agolpaba 
contra los edificios y cubría las ruinas... La marea subía cegando ventanas, ahogándolo todo, amontonando sedimento más allá de toda comprensión y medida." ${ }^{24}$

En sus pesquisas, Andrés se topa con un viejo cartógrafo que vive en la Biblioteca Nacional, un emblema del pasado, totalmente abandonada. Él le hace notar que su amigo había estado relacionando nomenclaturas de calles ya abandonadas con lugares de la Luna, también le muestra una serie de mapas sobre la pared: "En ellos podía verse desde la litografía de un valle rodeando un lago prehistórico, hasta los últimos y detallados planos urbanos" 25 y le explica:

Como todas las ciudades imperiales, la nuestra se erigió sobre un modelo cosmogónico. La ciudad, con su lago al centro, era un espejo del cosmos... El valle que contiene la ciudad fue en otro tiempo un lugar lagunoso. El nombre antiguo de la Ciudad significa el ombligo de la luna. Los mitos más antiguos refieren que la Luna surgió del fondo del lago donde estaba asentada la Ciudad. ${ }^{26}$

En "Tumbaga, El valle de las campanas" de César Rojas, la ciudad presenta un escenario parecido al de "Tiempo lunar", pero mucho más emponzoñado: "los estruendos bélicos, sísmicos y atmosféricos habían hundido a la ciudad en lagos de ácidos y carroña" ${ }^{27}$. En esta historia, el estilo rudo del sobreviviente a la catástrofe atómica, al estilo Mad Max, se conjuga con el neomexicanismo que idealiza el pasado precolombino, para generar un escenario postapocalíptico en el que renace de "las ruinas del valle pantano" la nueva "raza de cobre". Llamados por una voz milenaria: "Los que habían sobrevivido al hundimiento y los temblores y la guerra... semibárbaros, semidiotas, enfermos desde antes del nacimiento... llegaron a la isla de nombre Basílica, en cuyo centro se elevaba la pirámide de Guadalupe Tonantzin, construida con escombros en medio del líquido fermentante." 28

“A las 12 del día 12 del mes 12 de 2025, ante las muchedumbres que ascendían a adorar las campanas... aparece el teñidor, lleno de fetidez y llagas. Aquel cuyo nombre en la lengua española ya estaba olvidado, mas cuyo nombre en el habla de la tierra decíase Nanahuatzín"29. Al tiempo que hace sonar las campanas con frenesí, con el grito hipnótico y repetitivo de ¡tumbaga! crea una catarsis colectiva y los volcanes dormidos comienzan a hacer erupción:

De pronto, como armonía inexorable al canto tumbaga, una primera secuencia de truenos sacudió los cuerpos y las tierras y los lodos. Era un sonido telúrico, prolongado, semejante a viento mórbido del subsuelo, que los viejos pudieron aún identificar como ese preludio pánico a los terremotos y borrascas nucleares que habían transustanciado la megalópolis en Pantano... Y explotó la atmósfera en oleadas de estallidos que anunciaban la resurrección de las montañas centinelas del Valle. El campanero chillaba, las campanas ululaban, retumbaban los terráqueos tambores llamados volcanes que de nuevo, al llamado, al unísono revivían para purificar por el fuego los fermentos pútridos del pantano. ${ }^{30}$

\section{5}

Un segundo relato de César Rojas "El que llegó al metro Pino Suárez", es a mi parecer el cuento más completo e inquietante de los leídos. Logra crear un ambiente terrible y verosímil, pero sobretodo seduce su personaje: "el valedor", "trovador de veras", que viaja con su chava y con su guitarra, abriéndose las puertas en medio de la barbarie postapocalíptica con sus rolas. El autor recupera el habla popular de las zonas 
marginales de la urbe y con gran poética la recrea planteando tácitamente que este es el español que sobrevivirá al "day after":

Si llegas al Distrito te me partes

Más fuerte te contaminas

Más gacho los muertos jieden

Y te chillan los oclayos

Y los cuates se te aguadan

Nomás llégale al Distrito

Y le diste para siempre

Chicharrón a la esperanza. ${ }^{31}$

Los Pancholares", "la banda más fregona", le roban a su chava "en lo que antes era ciudad Neza", y él se lanza a rescatarla hasta lo que fuera el centro de la capital. El autor narra la aventura del trovador hacia las entrañas de la "capirucha": "Vi muchos despapayes y vi muchas mierdas, pero ni cuenta. Y olí muchas desgraciadeses y respiré muchas cochinadas, pero ni cuenta. $Y$ pasé por cascajos y por cráteres y por llanos que antes eran cerros y por cerros y más cerros de purititos desperdicios y purititos muertos, y por un pantano dizque venenoso que se me hace que antes era Bosques de Aragón." ${ }^{32}$ Finalmente llega a lo que fuera la gran central de abastos de la ciudad: "Ya ni había ni taquillas ni torniquetes, pero ahí entre los montones de basura y de difuntos y de pedazos de difunto, todavía estaba el postecito con el letrero que decía La Merced. ${ }^{33}$

Ahí, se encuentra con una banda de cómo cien Panchólares: "Unos tragando sus cachos de animales, otros sus buenas porciones de humanos y los huesos y la sangre se les escurrían de los hocicos con todo y babas o sino ahí andaban vomitando lo que acababan de tragarse, y unos hasta estaban dándose un toque con esas yerbas que ora salen como hongos de las ruinas y que palabra que ponen a uno más pacheco que la mota de antes." ${ }^{34}$ Es así como con sus canciones, que hacen llorar a los rudos sicarios, recupera a su chava. Pero ella ya contagiada del nuevo SIDA, que produce una muerte horrible y decadente, cuando él la libera se quita la vida enterrándose el cuchillo que le arrebata de su cinturón. Queda él, solo con su guitarra y sus canciones.

Es así como estas historias nos recuerdan que en ocasiones para hacer una prospección hacia el mañana es necesario comenzar por ahondar en el pretérito. No se puede entender la complejidad y efervescencia del México actual y futuro, sin acotar ciertos aspectos esenciales de su pasado. Se dice que México tiene una historia milenaria, esto lo confirman los impresionantes vestigios de las grandes civilizaciones desarrolladas a lo largo de su territorio. Sin embargo, el gran imperio Azteca, con su propia cosmogonía del mundo, con su organización social, su estética y arquitectura, etc., quedó supeditado a la visión de los vencedores, resultado de la conquista española; de ahí nació el mexicano actual, hijo de la colonización y el mestizaje. Es importante que incluyamos también, en la última era, el influjo determinante del imperialismo del vecino del norte, que se suma a una relación donde ese "México profundo" representado por los indígenas actuales (desindianizados, proletarizados), queda subyugado por el poder estatal y económico, esencialmente criollo.

Surge en paralelo una mística, una epopeya de la resurrección del mexicano postindígena, ciberpunk urbano, quien por sus venas corre sangre originaria y, a la vez, se ha adaptado a los nuevos tiempos. Es en este tono que oscilan las historias de César Rojas. Es el cholo, el chavo banda de Ciudad Neza reloaded, es el mestizo ciberpunk, bohemio, anarquista, quien sobrevive a la catástrofe, porque ya de entrada tenía todo perdido, porque ni la promesa de la modernidad era para él. En esta mitología, el agachado, el reprimido, el jodido, el que no alcanzó los bienes del progreso a la vez que 
fue desarraigado de su tierra y tradiciones indígenas, el que ya no puede perder nada porque no tiene nada que perder, resurge de la catástrofe empoderado.

\section{BIBLIOGRAFÍA}

BARTRA Roger, La jaula de la melancolía, Identidad y metamorfosis del mexicano, Editorial Grijalbo. México, 1987.

BONFIL BATALLA Guillermo, México profundo Una civilización negada, Libros de Bolsillo, México, 1983.

CASTELLANOS Laura, Las profecías del fin del mundo, Editorial Grijalbo. México, 2011.

FERNÁNDEZ Bernardo (El Bef) (antologador), Los viajeros, 25 años de ciencia ficción mexicana. Ediciones SM México, 2010.

FERNÁNDEZ Delgado Miguel Ángel (compilador), Visiones periféricas, Antología de la ciencia ficción mexicana, Editorial Lumen, México, 2001.

MOLINA Mauricio, Tiempo lunar, Editorial Eco / Osa Mayor. México, 1993.

MONSIVAIS Carlos, Apocalipstick, Editorial Debate. México, 2009.

PAGE Max, The city's End, Two centuries of fantasies, fears, and premonitions of New York's destruction, Yale University Press, USA, 2008.

TRUJILLO MUÑOZ Gabriel (compilador), El futuro en llamas, Cuentos clásicos de la ciencia ficción mexicana, Grupo Editorial Vid. México, 1997.

\section{NOTAS}

1. Para una información pormenorizada de la historia de la literatura de ciencia ficción en México, consultar la "Breve crónica de la ciencia ficción mexicana" texto introductorio de Gabriel Trujillo Muñoz (compilador) El futuro en llamas. Cuentos clásicos de la ciencia ficción mexicana Grupo Editorial Vid. México, 1997.

2. OP. Cit. p. 26

3. Carlos Monsivais. Apocalipstick. Editorial Debate. México, 2009. pp. 27-28.

4. OP. CIT. p. 30

5. IBID. p. 29

6. Citado por Bernardo Fernández, el Bef (antologador) Los viajeros. 25 años de ciencia ficción mexicana. Ediciones SM México, 2010. p. 12.

7. OP. CIT. p. 11

8. Hector Chevarría en: Miguel Ángel Fernández Delgado (compilador) Visiones periféricas. Antología de la ciencia ficción mexicana. Editorial Lumen. México, 2001. p. 120.

9. Vagabundo, generalmente alcohólico y drogadicto.

10. Gonzalo Mastré en: OP. CIT. pp. 131-132.

11. IBID. p. 137. 
12. José Emilio Pacheco en: Gabriel Trujillo Muñoz (compilador) El futuro en llamas. Cuentos clásicos de la ciencia ficción mexicana Grupo Editorial Vid. México, 1997. p. 190.

13. OP. CIT. p. 191.

14. IBID. p. 196.

15. Ignacio Padilla en: Bernardo Fernández, el Bef (antologador) Los viajeros. 25 años de ciencia ficción mexicana. Ediciones SM México, 2010. p. 90.

16. OP. CIT. p. 91.

17. Bernardo Fernández, el Bef en: Bernardo Fernández, El Bef (antologador) Los viajeros. 25 años de ciencia ficción mexicana. Ediciones SM México, 2010. p. 168.

18. OP. CIT. p. 169.

19. IBID. p. 170

20. IBID. p. 176.

21. Pintor mexicano, nacido en 1910 , autor de famosos cromos de calendario que resaltan la mística indigenista mediante una estética profundamente kitsch y de gran recepción popular. Su imagen más famosa y multirreproducida es la representación antropomórfica de estos volcanes como pareja de superdotados príncipes indígenas.

22. Laura Castellanos. 2012 Las profecías del fin del mundo. Editorial Grijalbo. México, 2011. p. 57.

23. Mauricio Molina Tiempo lunar. Editorial Eco / Osa Mayor. México, 1993. p. 21

24. OP. CIT. p. 73.

25. IBID. p. 54.

26. IBID. p. 73

27. Cesar Rojas en: Miguel Ángel Fernández Delgado (compilador) Visiones periféricas. Antología de la ciencia ficción mexicana. Editorial Lumen. México, 2001. p. 124.

28. OP. CIT. p. 125.

29. IBIDEM.

30. IBID. p. 126.

31. César Rojas en: Bernardo Fernández, El Bef (antologador) Los viajeros. 25 años de ciencia ficción mexicana. Ediciones SM México, 2010. p. 216.

32. OP. CIT. p. 217.

33. IBID. p. 218.

34. IBID. p. 220.

\section{RESÚMENES}

Este ensayo analiza unos cuantos cuentos de ciencia ficción realizados por autores mexicanos, en los que se trata el tema del futuro de la ciudad de México, generalmente en tono distópico. Al parecer hay ciudades con mayor potencial apocalíptico, como la ciudad de Manhattan, que ha sido objeto de todas las destrucciones y las plagas megaproducidas por Hollywood. La ciudad capital mexicana no se queda atrás, es identificada como uno de los centros más caóticos y apoteóticos del orbe. Revisaré ese escenario a través de las pautas del género de la ciencia ficción como diagnóstico del presente; así mismo, buscaré el rastro de ese futuro imaginario que no solo ha llegado, sino que ha sido rebasado por nuestro presente.

Cet essai analyse plusieurs contes de science-fiction mexicains qui abordent le thème du futur de la ville de Mexico sur un ton généralement dystopique. Il semble qu'il y ait des villes avec un plus 
grand potentiel apocalyptique comme Manhattan, qui a été l'objet de toutes les destructions et les fléaux infligés par Hollywood. La capitale mexicaine n'est pas en reste puisqu'elle est identifiée comme l'un des centres les plus chaotiques et apothéotiques de la planète. Je m'intéresserai à cette ville à partir des normes du genre de la science-fiction comme diagnostic du présent; c'est ainsi que je chercherai les traces de ce futur imaginaire qui non seulement s'est déjà concrétisé, mais est largement dépassé par notre présent.

\section{ÍNDICE}

Palabras claves: apocalipsis, futuro, ciencia ficción, modernidad, ciudad, México, Distrito Federal (DF)

\section{AUTOR}

\section{ITALA SCHMELZ}

Curadora y crítica de arte, México 